\title{
Effects of hunger on responses to demand characteristics in the measurement of persuasion'
}

IRWIN SILVERMAN, University of Florida, Gainesville, Fla. 31601, and ARTHUR D. SHULMAN, Washington University, St. Louis, Mo. 63110

The two studies reported here attempted to account for prior discrepant findings regarding the effects of eating upon persuasion, based on the contention that hungry Ss show a lesser responsiveness to demand characteristics which is manifested in lower persuasion scores. The findings of the first study were that, for females only, hunger related negatively to responsiveness to demands $(p<.01)$ and to persuasion $(p<.15)$, and persuasion related positively to responsiveness to demands $(p<.15)$. Similarly, the findings of the second study were that, for females only, hungry $S$ s showed less persuasion when the $E$ indicated personal agreement with the persuasive message than when he indicated disagreement and these effects were reversed for nonhungry Ss. Confidence levels for this interaction were .06 and .15 for the two measures of hunger used.

Janis, Kaye, \& Kirschner (1965) showed that refreshments given to $S$ s by the $E$ during the reading of persuasive messages increased persuasion, based on the contention that refreshments operated as an "unconditioned stimulus" and the positive responses they elicited became generalized to the content of the messages. A further study (Dabbs \& Janis, 1965), however, tested the alternate proposition that refreshments heightened the motives of the Ss to please the $E$ by complying with implicit "demands" (Orne, 1962) for persuasion. The effects of refreshments were assessed under conditions in which they were served either prior to or during the reading of the messages, and under conditions in which $\mathrm{E}$ indicated to $\mathrm{Ss}$ either personal agreement or disagreement with the messages. It was considered that the conditioning interpretation would be sup ported if persuasion were increased in both agreement and disagreement conditions, but only when refreshments were served during the reading, while the "compliance with demands" view would be supported if persuasion were increased in the agreement condition and decreased in the disagreement condition under both refreshment conditions. The findings did not support either view; refreshments increased persuasion in the agreement condition and decreased persuasion in the disagreement condition, but only when they were served during the reading of the messages.

In the attempt to develop an explanation of these data, the present investigators noted that in both studies, refreshment and control groups were administered the procedures at hours when they would be expected to be hungry. It was considered that the frustration of being kept from food by the experiment may make hungry Ss less responsive to E's demands or cause them to give responses opposite to these (cf. Silverman \& Kleinman, 1968). This would suggest why the responses of Dabbs and Janis' nonrefreshment group conformed less to the E's expressed opinions than the group eating during the messages, who were appeasing their hunger. It may also explain why the greater conformity of the refreshment group occurred only when Ss were eating during the messages, if we assume that hungry Ss who had imbibed a small amount of refreshment some time before would again feel hungry. The studies described in the present report were based on these contentions.

In the first study, measures were taken of the tendency to comply with demand characteristics, persuasibility, and hunger. Expectations were that compliance with demands and persuasibility would be positively related and that hunger would be negatively related to both variables.

\section{STUDY 1}

Procedure

Subjects (174 female and 113 male introductory psychology students) were administered the measures in groups of approximately 25 , at different times during the afternoon to maximize the variability of hunger.

The measure of compliance with demands, administered first, consisted of Ss rating 15 words with noun and verb forms (e.g., dream), each successively as a noun and as a verb, on the scale labelled active-passive of the semantic differential. The extent to which the $S$ rated verb forms more active than noun forms was the criterion for compliance with demands, evidence for which is contained in a prior report (Cataldo, Silverman, \& Bown, 1967). The persuasion measure consisted of five messages, each followed by two opinion items, described in Silverman, Ford, \& Morganti (1966). Hunger was rated by having the $S$ at the end of the session indicate the time since he had food of any kind, which was coded into $1 / 2-h$ units.

Results and Discussion

Females were significantly higher and more variable than males on both the measures of compliance with demands and time since last food intake. (For the means, $\mathrm{t}=3.07, \mathrm{p}<.05$, and $\mathrm{t}=3.00, \mathrm{p}<.05$, respectively. For the variances, $F=1.59$, $\mathrm{df}=112,173, \mathrm{p}<.05, \quad$ and $\mathrm{F}=2.11$, $\mathrm{df}=112,173, \mathrm{p}<.01$, respectively.)

The sex difference for mean compliance is consistent with prior data (cf. Rosenthal, 1966, p. 226) that female Ss show more E expectancy effects, and suggests that females are more responsive to "demands" in general, whether contained in E's behavior or in the experimental design. The difference in mean time since last food intake may indicate either that females were hungrier or that they require less food.

The correlations among the three measures for males were of zero order magnitude. For females, they were in the predicted directions. The rs were: Hunger by Compliance with Demands, $-.19(p<.01)$; Hunger by Persuasion, $-.11(\mathrm{p}<.15)$; Compliance with Demands by Persuasion, $.12(\mathrm{p}<.15)$.

These data may suggest that the predicted relationships occur for females only, and this contention was the basis of the second study. In this study, rather than measuring the tendency to comply with demands, these were manipulated in the manner of Dabbs \& Janis (1965).

\section{STUDY 2}

Procedure

Subjects ( 108 females and 81 males) were from the same population as Study 1 and were similarly seen in groups of about 25 during various afternoon hours.

The persuasion measure consisted of two of the five communications of Study 1, arbitrarily selected (the ones involving von Hindenberg and abstract art). Unlike Study 1, E delivered the task instructions verbally and for half the Ss he followed with the statement: "Each article expresses one point of view about a controversial issue, whereby people could just as readily agree or disagree. I, personally, agree with the points of view of both articles, but you may have opposite opinions. Answer as you honestly see fit." For the balance of Ss, the phrase "I personally agree" was replaced by "I personally disagree."

The session concluded with the question regarding time since last food intake and, also, with an item asking Ss to report how hungry they felt at the moment on a scale of very, moderately, slightly, and not at all. This was designed to exclude error variance based on differential appetites.

Predictions were that for females only, hungry Ss would show less persuasion under 
Table 1

Mean Persuasion Scores by Sex of Subject, Agree vs Disagree Conditions, and Hunger (using the Hours since Last Food Measure)

\begin{tabular}{llcccc}
\hline & & \multicolumn{2}{c}{ Males } & \multicolumn{2}{c}{ Females } \\
& & N & Mn & N & Mn \\
\hline \multirow{3}{*}{ Hungry } & Agree & 26 & 18.23 & 33 & 17.97 \\
& Disagree & 13 & 18.46 & 23 & 19.39 \\
\multirow{3}{*}{ Not Hungry } & Agree & 24 & 17.89 & 34 & 19.38 \\
& Disagree & 18 & 19.88 & 28 & 18.36 \\
\hline
\end{tabular}

the agree condition and more under the disagree condition than nonhungry Ss.

Results and Discussion

The sole main effect of sex was that, counter to Study 1, males were more variable on time since last food intake $(F=1.67, \mathrm{df}=80,107, \mathrm{p}<.01)$.

Table 1 shows the mean persuasion scores by sex, agree vs disagree conditions, and hunger, using the measure of time since last food intake (coded as in Study 1 and divided by a median split). Table 2 shows the same data using the self-report hunger measure (divided into very or moderately vs slightly or not at all).

For both analyses of variance, interactions between hunger and agree vs disagree were nil $(F<1)$ for males. For females, they were in the expected directions and approached significance $(F=3.80, p<.06$, using the self-report measure; $F=2.40$, $\mathrm{p}<.15$, using the time measure; $\mathrm{df}=1,104$ for both). The three-way interaction terms for these effects were: $F=2.08, p<.15$, using self-report; $F=2.20, p<.10$ using time; $\mathrm{df}=1,181$ for both.

Considering both studies, although no single analysis permits a firm conclusion, the patterns of results with the two paradigms are quite congruent and provide a strong suggestion that for females only hunger produced less compliance with $\mathrm{E}$ demands on a persuasion test.

One possible explanation for the sex specificity of this relationship is based on a finding by Silverman (1967) using the same $S$ population as the present studies, that females, to a greater extent than males, tended to acquiesce more to a persuasive message when it was presented in the context of a psychological experiment than when it was not. This suggested that females, more than males, respond to persuasion tests in terms of their demand characteristics.

Table 2

Mean Persuasion Scores by Sex of Subject, Agree vs Disagree Conditions, and Hunger (Using the Self-report Measure)

\begin{tabular}{llrcccc}
\hline & & \multicolumn{2}{c}{ Males } & \multicolumn{2}{c}{ Females } \\
& & N & Mn & N & Mn \\
\hline \multirow{3}{*}{ Hungry } & Agree & 19 & 18.68 & 20 & 17.45 \\
& Disagree & 9 & 19.78 & 11 & 20.18 \\
Not Hungry & Agree & 25 & 17.64 & 37 & 19.16 \\
& Disagree & 28 & 19.25 & 40 & 18.45 \\
\hline
\end{tabular}

The present data may offer some resolution of the paradoxical findings of Dabbs and Janis, although their $S$ sample described as "Yale College students" was probably male. It is a feasible conjecture, however, that the extent to which Ss respond to the demands of a particular experimental paradigm varies, not only between sexes within the same population, but among different student populations.

\section{REFERENCES}

CATALDO, J. F., SILVERMAN, I., \& BROWN, J. M. Demand characteristics associated with semantic differential ratings of verbs and nouns. Educational Psychological Measurement. $1967,27,83-87$.

DABBS, J. M., \& JANIS, I. Why does eating while reading facilitate opinion change?-An experimental inquiry. Journal of Experimental Social Psychology, 1965, 2, 133.

JANIS, I. L., KAYE, D., KIRSCHNER, P. Facilitating effects of "eating-while-reading" on responsiveness to persuasive communications. Journal of Personality \& Social Psychology, $1965,1,181-185$.
ORNE, M. On the social psychology of the psychological experiment: With particular reference to demand characteristics and their implications. American Psychologist, 1962, 17 , 776-783.

ROSENTHAL, R. Experimenter effects in behavioral research. New York: AppletonCentury-Crofts, 1966.

SILVERMAN, I. Role-related behavior of subjects in laboratory studies of attitude change. Joumal of Personality \& Social Psychology, 1968, 8, 343-348.

SILVERMAN, I., FORD, L. H., \&ORGANTI, J. B. Inter-related effects of social desirability, sex, selfesteem, and complexity of argument on persuasability. Joumal of Personality, 1966, 34, 555-568.

SILVERMAN, I., \& KLEINMAN, D. A response deviance interpretation of experimentally induced frustration on prejudice. Joumal of Experimental Research in Personality, 1967, 2, 150-153.

\section{NOTE}

1. This study was supported by Grant No. GS-1945 from the National Science Foundation to the first au thor.

\section{Retrieval cues and meaningfulness in short-term recall}

\section{THOMAS O. NELSON, ${ }^{1}$ University of Illinois, Urbana, Ill. 61801}

The effect of retrieval cues ( $R C$ s) on the short-term recall of CCC items was explored. Three types of RCs were used: facilitative (correct letter), interfering (wrong letter), and neutral (no letter). It was hypothesized that the effect of RCs would be accentuated with high-meaningfulness (M) items and attenuated with low-M items. Forty-two college Ss were individually run through 36
Peterson short-term memory trials. Although the main effects of both $R C$ and $M$ were significant, the $R C$ by $M$ interaction was not significant, contrary to prediction.

Category names as retrieval cues (RCs) have been shown to facilitate free recall (e.g., Tulving \& Osler, 1968). Loess \& Harris (1968) demonstrated that categoryname RCs can facilitate the short-term recall of word triads. The present study 